\title{
Synonymy of Mycobacterium simiae Karasseva et al. 1965 and Mycobacterium habana Valdivia et al. 1971
}

\author{
J. G. WEISZFEILER AND ERICA KARCZAG \\ Microbiological Research Group, Hungarian Academy of Sciences, Budapest, Hungary
}

\begin{abstract}
On the basis of their physiological and biochemical properties and their antigenic structures, as revealed by gel diffusion systems, Mycobacterium simiae Karasseva et al. 1965 and Mycobacterium habana Valdivia et al. 1971 are regarded as belonging to the same'species. The correct name of this species, i.e., the legitimate name which has priority, is $M$. simiae. $M$. habana is thus a later subjective synonym of $M$. simiae.
\end{abstract}

Karasseva et al. (6) investigated spontaneous mycobacterial infections of monkeys and isolated numerous mycobacteria which differed in several properties from the known species of Mycobacterium. The isolates were identified as belonging to a new species, Mycobacterium simiae. $M$. simiae grows slowly and does not form pigment in the dark, but it has proved to be more or less photochromogenic. Representative strains caused severe lesions in mice. Further investigations (16) have shown that the isolates can be classified into two groups on the basis of biochemical and cultural properties and antigenic structure. The type strain of $M$. simiae (strain 29) was deposited in the American Type Culture Collection (14) and assigned the number 25275. Four strains were identified as $M$. asiaticum $\mathrm{sp}$. nov. (17). Boisvert (1) of the Pasteur Institute isolated three strains of $M$. simiae: two from humans and one from a monkey. Both patients had been in Africa; one of them shed the bacterium in his sputum after having returned to France. Krasnow and Gross (8) reported on a case of $M$. simiae infection in the United States.

Valdivia et al. (13) isolated mycobacteria from sputum samples from 35 patients in $\mathrm{Ha}$ vana; the strains were identified as belonging to $M$. habana. In a colloquium held in Antwerp in 1972, Valdivia (12) presented 10 additional human cases yielding $M$. habana. The properties of $M$. habana, including its niacin-positive reaction, were investigated by Pattyn and Domisse (10). It was shown that M. habana was weakly agglutinated by the antiserum of the Darden serotype of $M$. intracellulare. According to Boisvert, $M$. habana is identical with $M$. simiae. Meissner (9) examined seven strains of $M$. simiae, two strains of $M$. asiaticum, and three strains of $M$. habana. The $M$. simiae strains could be classified into two serotypes, namely, serotype I (strain 21) and serotype II (strain 59). The $M$. habana strains were agglu- tinated, up to the dilution $1: 60$, by the antiserum to serotype $I$, and strains 20,25 , and 29 of $M$. simiae were agglutinated by the $M$. habana antiserum. Accordingly, M. habana proved to be identical with $M$. simiae serotype I. Käppler and Neubert (5) established that the biochemical properties and drug resistance spectra of $M$. habana and $M$. simiae are identical. They concluded that the two species belong to a single complex.

The investigation of the antigenic structure of mycobacteria by the gel-precipitation method has proved to be a very reliable method for demonstrating common antigenic components in different strains and for establishing the degree of relationship between strains $(7,15,16)$. The identities of strains can be demonstrated by cross-absorption of the common antigens, and monospecific sera can be obtained by absorption with heterologous antigens. Based on these experiments, it seemed justified to apply the gel diffusion method to a comparative antigen analysis of $M$. simiae and $M$. habana.

\section{MATERIALS AND METHODS}

Bacterial strains. The type strain of $M$. simiae (strain 29 = ATCC 25275) was used to prepare antiserum in sheep (14). The antigenic structure of each of the following strains was examined: $M$. simiae 29 (ATCC 25275), $M$. habana 337, $M$. habana 4238 obtained from M. Kubín, Prague, $M$. avium ATCC 15768, $M$. kansasii ATCC 12478 , and $M$. smegmatis ATCC 14468, the latter three obtained from the American Type Culture Collection, Rockville, Md.

Methods. The strains were grown in liquid Sauton medium. The harvested pellicle was collected on filter paper, washed with $0.9 \% \mathrm{NaCl}$ solution, stirred with silicium carbide, extracted by cold $\left(4^{\circ} \mathrm{C}\right)$ saline, and centrifuged at 4,000 rpm for $15 \mathrm{~min}$. The supernatant was used as the cell-free antigen. It was standardized, with bovine serum protein as the standard, to contain $1 \%$ protein. Serum absorption and gel diffusion were performed as described previously (18). 
In addition, some biochemical properties of $M$. simiae and $M$. habana were determined. The biochemical methods used were described previously by Bönicke (2), Käppler (4), and Wayne et al. (14).

TABLE 1. Biochemical properties of $M$. simiae strain 29 and two strains of $M$. habana

\begin{tabular}{lcc}
\hline \multicolumn{1}{c}{ Test } & M. simiae strain & $\begin{array}{c}M . \text { habana } \\
\text { strains } 337 \text { and } \\
\end{array}$ \\
& 29 & 4238 \\
\hline Photoreactivity & + & + \\
Niacine & + & + \\
Phosphatase & - & - \\
Nitrate reductase & - & - \\
Urease & + & + \\
Nicotinamidase & + & + \\
Pyrazinamidase & + & + \\
\hline
\end{tabular}

\section{RESULTS}

The main biochemical characteristics of the type strain of $M$. simiae and the two strains of $M$. habana are shown in Table 1. The biochemical properties of 13 other strains of $M$. simiae were published in another paper (16). Strains of both species proved to be weakly photoreactive and niacin positive. Their enzyme reactions were identical.

The results of the immunodiffusion reactions are summarized in Table 2 and illustrated in Fig. 1 to 3 . The anti-M. simia serum formed 12 to 16 precipitation lines by titration with the homologous $M$. simiae antigen and the $M$. $h a-$ bana antigens as well. The lines of the homologous $M$. simiae system could be demonstrated

TABLE 2. Number of precipitation lines in gel diffusion reactions of $M$. simiae and $M$. habana antigens with unabsorbed $M$. simiae antiserum and the same antiserum after absorption by $M$. habana antigen and consecutively by $M$. kansasii, $M$. avium, and $M$. smegmatis antigens

\begin{tabular}{|c|c|c|c|c|c|c|}
\hline \multirow{2}{*}{ Immunoserum } & \multicolumn{6}{|c|}{ No. of precipitation lines } \\
\hline & $\begin{array}{l}\text { M. simiae } \\
29\end{array}$ & M. habana & $\begin{array}{l}\text { M. habana } \\
4238^{a}\end{array}$ & $\begin{array}{l}\text { M. kansasii } \\
\text { ATCC } 12478\end{array}$ & $\begin{array}{c}\text { M. avium } \\
\text { ATCC } 15768\end{array}$ & $\begin{array}{c}\text { M. smegmatis } \\
\text { ATCC } 14468\end{array}$ \\
\hline$M$. simiae 29 (not absorbed) & 16 & 16 & 16 & & & \\
\hline $\begin{array}{l}M . \text { simiae } 29 \text { absorbed by } M . h a- \\
\text { bana }\end{array}$ & 4 & 4 & 4 & & & \\
\hline $\begin{array}{l}M . \text { simiae } 29 \text { absorbed by } M . \\
\text { kansasii }+M \text {. avium }+M \\
\text { smegmatis }\end{array}$ & 4 & 4 & 4 & 0 & 0 & 0 \\
\hline
\end{tabular}

${ }^{a}$ Strains from M. Kubín, Prague, Czechoslovakia.

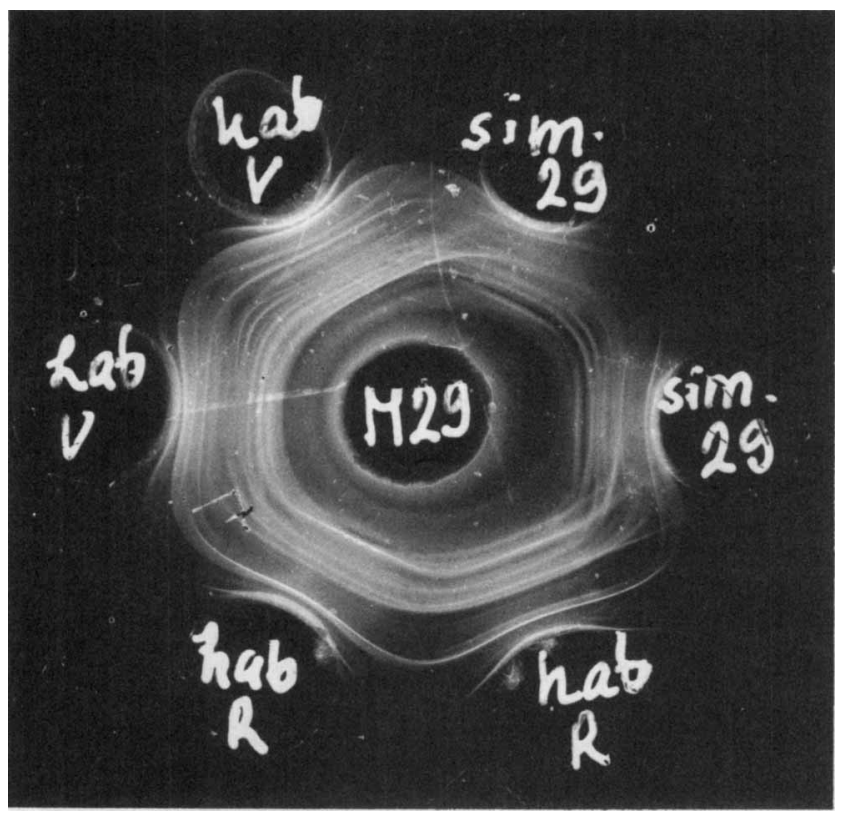

Fig. 1. Immunodiffusion reaction between $M$. simiae strain 29 antiserum (central wall $=$ M29) and antigens of M. simiae (sim 29), M. habana strain 337 (hab V), and M. habana strain 4238 (habR) antigens. 
in the simiae-habana system (Fig. 1), thus indicating that the two organisms are identical.

Figure 2 shows the reaction of the anti-simiae serum absorbed by the antigen of $M$. $h a$ bana. Since absorption with this antigen was not complete, the residual components had to be identified. The same four precipitation lines appeared in both the $M$. simiae and $M$. habana systems, indicating that no antigen absent in $M$. habana could be demonstrated in $M$. simiae. The position and intensity of the precipitation lines show that some antigenic components are in lower concentration in the $M$. simiae antigen than in the $M$. habana antigens.

The anti-simiae serum, which was absorbed stepwise by $M$. avium, $M$. kansasii, and $M$. smegmatis antigens, may be regarded as monospecific for $M$. simiae.

Figure 3 shows common precipitation lines between the $M$. simiae monospecific system and the M. habana antigens. Accordingly, the antigenic structures of $M$. simiae and $M$. habana proved to be identical in all three gel precipitation systems.

\section{DISCUSSION}

Boisvert (1) and Meissner (9) have shown that $M$. habana is not a distinct species of Mycobacterium, for it is identical with $M$. simiae, a species described in 1965 and thoroughly examined and characterized thereafter. Pattyn (10), on the other hand, is of the opposite opin- ion. A direct comparison of the antigenic structure of the two organisms seems to be the most reliable method of answering this question.

We have shown that the 16 antigens demonstrated by us in $M$. simiae are present in $M$. habana as well. Therefore, in our opinion, the latter does not represent a new species, and this is confirmed by the biochemical reactions of the organims. However, the biochemical tests have not been standardized, and this may explain why $M$. simiae strain 29 was found to be niacin negative and nitrate reductase positive by Pattyn and niacin positive and nitrate reductase negative by Boisvert (1), Käppler (5), Schröder (11), Meissner (9), and by us (15-17). M. habana, which we regard as a later subjective synonym of $M$. simiae, deserves interest as a human pathogen, especially in tropical countries. We believe that it is not by mere chance that this species has been isolated from humans in tropical countries, namely, Africa and Cuba: hot, humid climate favors its multiplication in nature. It is of special importance (9) that two serotypes of $M$. simiae could be differentiated: serotype I (strain 29) and serotype II (strains 55, 58, and 59). Earlier, we $(15,17)$ observed some differences among strains identified by us as $M$. simiae, but we attributed these divergencies to strain variability. A relationship between $M$. simiae and the "avium-intracellulare" group is suggested by the eight common antigens demonstrable by the gel precipitation

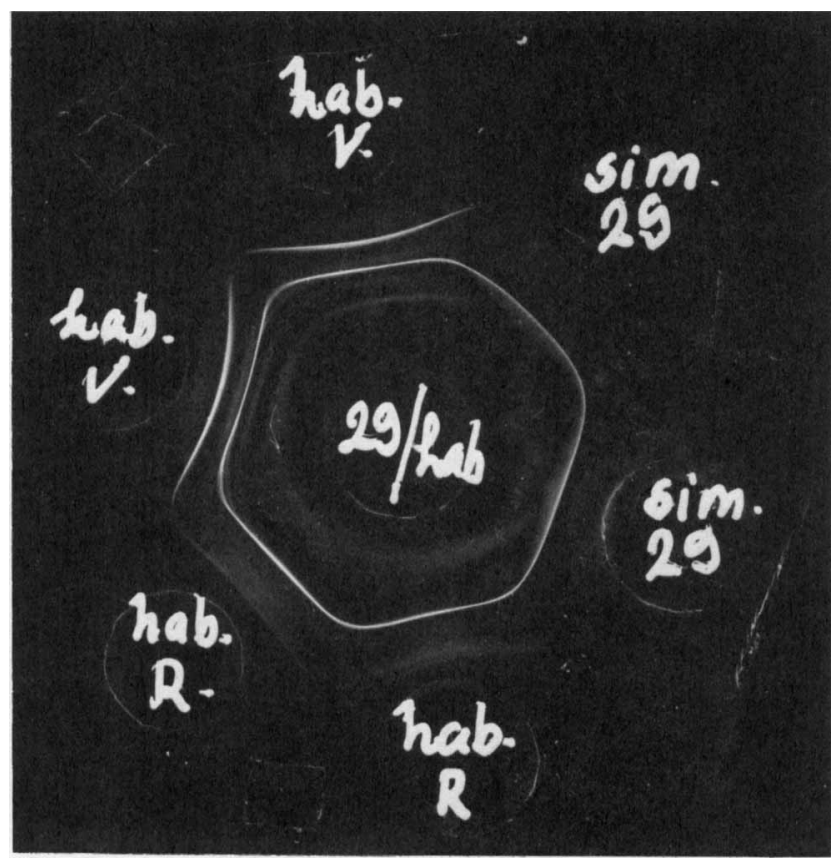

FIG. 2. Immunodiffusion reaction between $M$. simiae antiserum absorbed by the antigen of $M$. habana (29/ hab) and the antigens of $M$. simiae ( $\operatorname{sim} 29$ ) and $M$. habana (hab $R$ and hab V). 


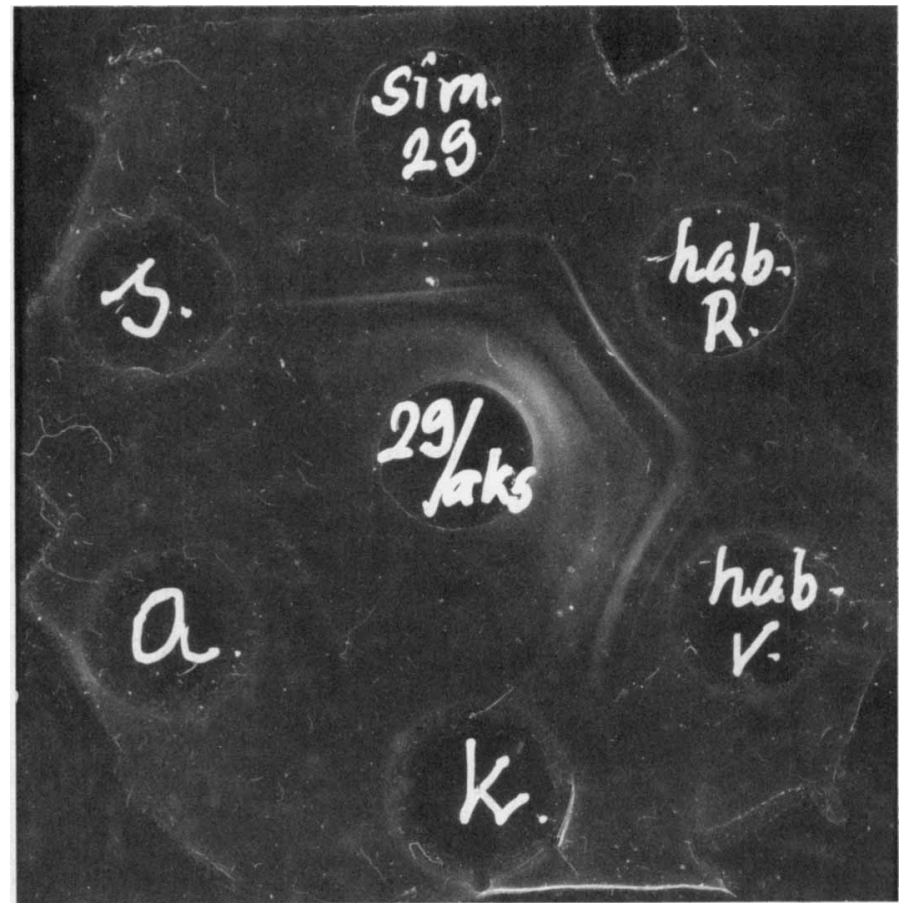

FIG. 3. Immunodiffusion reaction between $M$. simiae strain 29 antiserum absorbed by $M$. avium $+M$. kansasii $+M$. smegmatis (29/aks) antigens and the $M$. simiae (sim 29), M. habanna (hab $R$ and hab V), $M$. kansasii (k), M. avium (a), and $M$. smegmatis (s) antigens.

test and by the cross-agglutination reactions at low titer, demonstrated by Pattyn (10) and Meissner and Schröder (9). We (16) have also noted this antigenic relationship.

\section{REPRINT REQUESTS}

Address reprint requests to: Dr. J. G. Weiszfeiler, Microbiological Research Group, Hungarian Academy of Sciences, Budapest, Hungary.

\section{LITERATURE CITED}

1. Boisvert, H. 1973. Mycobactéries ( $M$. bovis et "atypiques") identifiées a l'Institut Pasteur de Paris de 1960 1972, p. 29-41. In The genus Mycobacterium. Prince Leopold Institute of Tropical Medicine, Antwerp.

2. Bönicke, R. 1962. Identification of Mycobacteria by biochemical methods. Bull. Int. Union Tuberc. 32:13-68.

3. Käppler, W. 1970. Identification of atypical mycobacteria from monkeys. Proc. Microbiol. Res. Group Hung. Acad. Sci. 3:71-72.

4. Käppler, W. 1971. Beitrag zur Artbestimmung von Mykobakterien. Z. Erkr. Atmungsorgane. 135:39-51.

5. Käppler, W., and R. Neubert. 1974. Identifizierung und Differenzierung von Mycobacterium habana, Z. Erkr. Atmungsorgane 141:262-268.

6. Karasseva, V., J. G. Weiszfeiler, and E. Krasznay. 1965. Occurrence of atypical mycobacteria in Macacus rhesus. Acta Microbiol. Acad. Sci. Hung. 12:275-282.

7. Karczag, E., and J. G. Weiszfeiler, 1973. Antigenic structure of $M$. simiae and $M$. asiaticum, p. 193. In J. G. Weiszfeiler (ed.), Atypical mycobacteria. Akadémiai Kiadó, Budapest.

8. Krasnow, I., and W. Gross. 1975. M. simiae infection in the United States. Am. Rev. Resp. Dis. 111:357-360.
9. Meissner, G., and K. Schröder. 1975. Relationship between Mycobacterium simiae and Mycobacterium habana. Am. Rev. Resp. Dis. 111:196-200.

10. Pattyn, S. R., and R. Domisse. 1973. Bacteriological study of Mycobacterium habana, p. 63-69. In The genus Mycobacterium. Prince Leopold Institute of Tropical Medicine, Antwerp.

11. Schröder, K. 1970. Mycobacterium simiae (preliminary report). Proc. Microbiol. Res. Group Acad. Sci. Hung. 3:41-45.

12. Valdivia, J. A. 1973. Mycobacterium habana: clinical and epidemiological significance, p. 59-62. In The genus Mycobacterium. Prince Leopold Institute of Tropical Medicine, Antwerp.

13. Valdivia, A., J. S. Méndez, and M. E. Font. 1971. Mycobacterium habana: probable nueva especie dentro dellas micobacterias no classificadas. Bol. Hig. Epidemiol. Habana 9:65-73.

14. Wayne, L. G., J. R. Doubek, and R. L. Russell. 1964. Classification and identification of mycobacteria. I. Tests employing Tween 80 as substrate. Am. Rev. Resp. Dis. 90:588-597.

15. Weiszfeiler, J. G. 1969. Die Biologie und Variabilität des Tuberkelbakteriums und die atypischen Mykobakterien, p. 247. Akadémiai Kiadó, Budapest.

16. Weiszfeiler, J. G., V. Karasseva, and E. Karczag. 1970. Studies on Mycobacterium simiae and some other atypical mycobacteria isolated from monkeys. Proc. Microbiol. Res. Group Hung. Acad. Sci. 3:31-39.

17. Weiszfeiler, J. G., V. Karasseva, and E. Karczag. 1971. A new Mycobacterium species: Mycobacterium asiaticum. Acta Microbiol. Acad. Sci. Hung. 18:247-252.

18. Weiszfeiler, J. G., I. Jókay, E. Karczag, K. Almássy, and P. Somos. 1968. Taxonomic studies on mycobacteria on the basis of their antigenic structure. Acta Microbiol. Acad. Sci. Hung. 15:69-76. 